\title{
O CONTROLE SOCIAL COMO PRÁTICA CIDADÃ: UMA ANÁLISE DA ATUAÇÃO DO CONSELHO MUNICIPAL DE SAÚDE DE PALMAS-PR EM $2017^{1}$
}

\author{
SOCIAL CONTROL AS CITIZEN PRACTICE: AN ANALYSIS OF THE \\ ACTIVITY OF THE MUNICIPAL HEALTH COUNCIL OF PALMAS-PR IN 2017
}

\author{
Marlon Silvestre Kierecz ${ }^{*}$ \\ Tania Ramos Bartmeyer ${ }^{* *}$ \\ Lislei Teresinha Preuss ${ }^{* * *}$
}

\begin{abstract}
RESUMO
O presente trabalho visa analisar de que maneira o controle social na esfera da saúde ocorreu no município de Palmas-PR, em específico no Conselho Municipal de Saúde, no ano de 2017. Foi construído por meio de pesquisa teórica e análise de dados, com referencial teórico pautado nos autores que discutem sobre cidadania, controle social, democracia, e políticas públicas (sociais). Trará uma abordagem crítica sobre participação, contextualização e efetivação do direito e das políticas públicas, assim como, a formação dos conselhos municipais de saúde, ponderando perspectivas a partir do temário. Abarcará uma análise de dados referente as atas do Conselho Municipal de Saúde do ano de 2017, apontando elementos de composição, participação social, votações, capacitação e controle das pautas. Os resultados demonstram que a composição não é paritária, que a participação efetiva de parte dos conselheiros não ocorre, que há dirigismo das pautas e votações unânimes. Concluir-se, também, que a quantidade de assuntos técnicos debatidos exige uma formação qualificada e específica para os conselheiros.
\end{abstract}

Palavras-Chave: Cidadania; Controle Social; Democracia Direta; Educação; Conselho Municipal de Saúde de Palmas-PR.

\begin{abstract}
This work aims to analyze how the social control in the health sphere occurred in the municipality of Palmas-PR, specifically in the Municipal Health Council, in 2017. It was built through theoretical research and data analysis, with a theoretical referential based on authors who discuss citizenship, social control, democracy, and public (social) politics. It will a critical approach on participation, contextualization and implementation of law and public policies, as well as the formation of municipal health councils, considering perspectives from the agenda. It will cover a data analysis referring to the minutes of the Municipal Health Council for the year 2017, pointing out elements of composition, social participation, voting, training and control of the guidelines. The results show that the composition is not parity, that the effective participation of the counselors does
\end{abstract}

\footnotetext{
${ }^{1}$ Artigo confeccionado para avaliação final da disciplina de Direitos e Proteção Social do Programa de Pós-Graduação em Ciências Sociais Aplicadas (Mestrado/ Doutorado).

*Doutorando em Ciências Sociais Aplicadas pela Universidade Estadual de Ponta Grossa. Professor do Instituto Federal do Paraná - campus Palmas. Estudante membro do Grupo de Pesquisa Agenda Social do Mercosul e Proteção Social no Brasil, registrado no CNPQ.

${ }^{* *}$ Assistente Social formada pela Universidade Estadual de Ponta Grossa-UEPG. Aluna especial do Mestrado em Ciências Sociais Aplicas, na disciplina Diretos e Proteção Social.

*** Doutora em Serviço Social pela Pontifícia Universidade Católica do Rio Grande do Sul. Professora Adjunta da Universidade Estadual de Ponta Grossa e do Programa de Pós-Graduação em Ciências Sociais Aplicadas (Mestrado/Doutorado). Pesquisadora membro do Grupo de Pesquisa Agenda Social do Mercosul e Proteção Social no Brasil, registrado no CNPQ.
} 
not occur, that there are dirigism of the voting rules and unanimous. It should also be concluded that the number of technical subjects discussed requires qualified and specific training for board members.

Keywords: Citizenship; Social Control; Direct Democracy; Education; Municipal Council of Health of Palmas-PR.

\section{INTRODUÇÃO}

São constantes as queixas em relação a qualidade e atuação dos representantes eleitos para o Congresso Nacional e para o Poder Executivo, em verdadeiro cenário de desilusão e pessimismo com a democracia representativa. No entanto, é importante lembrar que a democracia não se resume a votar em representantes, ela também é participativa e, em muitas situações, exercida de forma direta, como no caso dos Conselhos Municipais de Saúde, em que os cidadãos podem atuar como conselheiros.

Este breve artigo tem seu foco no exercício da cidadania por meio da participação nos Conselhos Municipais, tomando-se como exemplo de análise o Conselho Municipal de Saúde da cidade de PalmasPR. O que se indaga neste estudo, sobretudo, é se a participação popular direta tem tido a eficácia que dela se espera e se as condições para o seu exercício proporcionam a real emancipação do cidadão.

O Município de Palmas-PR e o seu Conselho de Saúde, foram escolhidos em razão de alguns dados preocupantes deste contexto. Sua população é estimada em 48.990 habitantes no ano de 2017 e sua taxa de escolarização entre os sujeitos de 6 a 14 anos é de $92,8 \%$. Isso faz desta cidade a penúltima colocada nesta categoria no Paraná, ocupando a $398^{\mathrm{a}}$ posição. No cenário nacional ocupa a $5.353^{\mathrm{a}}$ posição $\left(\mathrm{IBGE}^{2}\right)$. Ainda, o analfabetismo, com dados de 2010, entre pessoas com 15 anos ou mais é de 9,31\% e entre pessoas com 50 anos ou mais é de 21,77\% (IPARDES, 2018, p. 39). Estes dados sobre educação foram trazidos porquanto neste artigo far-se-á uma correlação entre participação popular, controle social e educação.

Ainda, o IDH de Palmas é de apenas 0,660 (2010), ocupando a 342a posição no Estado do Paraná, que conta com 399 municípios e $2.872^{a}$ posição no Brasil (IBGE) ${ }^{3}$. O índice GINI é de 0,5529 e a morta-

${ }^{2}$ https://cidades.ibge.gov.br/brasil/pr/palmas/panorama ${ }^{3} \mathrm{https}: / /$ cidades.ibge.gov.br/brasil/pr/palmas/panorama lidade infantil foi de 16,67 a cada 1.000 nascimentos em 2017, (IPARDES, 2018, p. 37-38), servindo de reflexo da situação da saúde na cidade.

A artigo é divido em três tópicos, sendo o primeiro sobre o processo de constitucionalização e efetividade dos direitos e políticas sociais no Brasil, notadamente sobre a saúde, em 1988 e uma consequente nova concepção de cidadania.

Posteriormente se discorrerá sobre a formação dos Conselhos Municipais de Saúde e como se dá a participação popular nestes órgãos, no efetivo exercício do controle social. Nesta seara será abordado o papel da educação na formação do sujeito para a prática da cidadania, e todos os percalços que podem ocorrer.

No último tópico serão tratados os dados específicos do Conselho Municipal de Palmas, com estatísticas e análises da atividade no ano de 2017 e; por fim, ter-se-á as considerações finais com a aglutinação do campo teórico com a realidade da prática no Conselho.

\section{A CONSTITUCIONALIZAÇÃO E EFETIVAÇÃO DO DIREITO E DAS POLÍTICAS PÚBLICAS DE SAÚDE}

É possível afirmar que antes da Constituição de 1988 ser cidadão era possuir a nacionalidade brasileira, uma vez que, direitos sociais como saúde e previdência somente eram garantidos aos trabalhadores formais. Com uma grande camada da população excluída da proteção social, não se podia falar em cidadania plena. A nova Carta Magna instituiu uma rede de proteção social, que inclui saúde, previdência e assistência social. À saúde foi garantido o acesso universal, sem a imposição de qualquer condicionante, independe do status, classe ou posição social (LOBATO, 2009).

A Constitucionalização de direitos sociais, como o acesso à saúde, no entanto, ainda enfrenta alguns obstáculos quanto a aplicabilidade e reconhecimento com status de direitos fundamentais. 
De acordo com o disposto no artigo $5^{\circ}, \S 1^{\circ}$ da Constituição Federal ${ }^{4}$, os direitos e garantias fundamentais têm aplicabilidade direta e imediata, ou seja, não precisam de outra norma que regulamente o exercício destes direitos para que sejam efetivos. Não há qualquer dúvida sobre esta aplicabilidade no que se refere aos direitos fundamentais de primeira geração, de liberdade negativa, que implicam numa imposição de abstenção do Estado em interferir no livre exercício de direitos, como liberdade, propriedade, reunião, etc., notadamente estampados no próprio artigo $5^{\circ}$. Ocorre que, além dos direitos individuais de autonomia subjetiva, os direitos fundamentais possuem um significado mais amplo, que compreendem também os direitos econômicos, sociais e culturais (PÉREZ LUÑO, 2013, p. 47).

Alguma dificuldade surge, porém, no que tange à aplicabilidade direta e imediata dos direitos sociais, notadamente o da saúde, de segunda geração, previsto no caput do artigo $6^{\circ}$ da Constituição ${ }^{5}$, cuja principal característica é a exigência de uma prestação positiva por parte do Estado, em efetivas políticas públicas, o que implica alto custo financeiro e manejo de grande estrutura física e organizacional.

$\mathrm{O}$ fato de o direito à saúde encontrar-se no artigo $6^{\circ}$ e não no artigo $5^{\circ}$ da Constituição é o primeiro obstáculo enfrentado para afirmar sua aplicabilidade direta e imediata, pois é o artigo $5^{\circ}$ que traz o rol de direitos fundamentais, o que, em tese, poderia implicar o direito à saúde ser uma norma programática ou pendente de regulamentação. Ocorre que, a Constituição não afirma, em qualquer dispositivo que esta eficácia, direta e imediata prevista no $\S 1^{\circ}$ não se estenda a outros direitos fora do rol do artigo $5^{\circ}$.

Perceba-se também que não se nega a aplicabilidade direta e imediata de outros direitos fora deste rol como o direito de greve $\left(\operatorname{art} .9^{\circ}\right)$, os direitos trabalhistas $\left(\operatorname{art} .7^{\circ}\right)$ ou os direitos políticos (art. 14). Ainda, o artigo $5^{\circ}, \S 2^{\circ}$, da Constituição ${ }^{6}$, expressamente, contempla a possibilidade de que outros direitos, previstos em diplomas diversos da própria Constituição, como

\footnotetext{
${ }^{4} \S 1^{\circ}$ - As normas definidoras dos direitos e garantias fundamentais têm aplicação imediata.

${ }^{5}$ Art. $6^{\circ}$ São direitos sociais a educação, a saúde, a alimentação, o trabalho, a moradia, o lazer, a segurança, a previdência social, a proteção à maternidade e à infância, a assistência aos desamparados, na forma desta Constituição.

${ }^{6} \$ 2^{\circ}$ - Os direitos e garantias expressos nesta Constituição não excluem outros decorrentes do regime e dos princípios por ela adotados, ou dos tratados internacionais em que a República Federativa do Brasil seja parte.
}

nos tratados internacionais, tenham esta mesma efetividade (SARLET, 2011, p. 263). Portanto, o texto constitucional em momento algum afirma ou dá a entender que os direitos sociais de cunho prestacional não teriam, também, aplicabilidade direta e imediata.

Diferentemente de outros direitos sociais que não possuem qualquer outra disposição tal qual a constante no artigo $6^{\circ}$ da Constituição Federal, o direito a saúde encontra especial disposição no artigo $196^{7}$, o qual inaugura uma seção inteira dedicada a matéria, o que deixa clara a especial preocupação com a tutela deste direito social por parte do legislador constituinte. As previsões deste artigo preconizam que a saúde é dever do Estado e todos, sem exceção, têm direito igual ao seu acesso.

Estas disposições revelam uma faceta consubstanciada no desenvolvimento do direito de solidariedade vertical que compreende as atividades desenvolvidas pelo Estado em busca de uma maior justiça social, bem como o oferecimento de serviços e benefícios sociais para os cidadãos. Trata-se da distribuição da riqueza gerada em prol da população mais vulnerável (MARTÍN, 2006, p. 58). Se a saúde é direito de todos, é universal e dever do Estado, significa que para a sua concretização, necessariamente, enormes despesas e estrutura precisariam ser disponibilizadas, à despeito da lógica do mercado.

A Constituição de 1988, no que tange às políticas públicas de saúde, adotou um modelo de competências comuns para o provimento dos serviços públicos sociais entre as três unidades federadas, o que acarreta uma série de discussões e confusões sobre quem é responsável por dado serviço e política pública. A concepção de atribuições comuns denota um projeto de federalismo cooperativo, no entanto, o que tem prevalecido é um caráter competitivo. A cooperação não parece um modelo próximo a vigorar, sobretudo, em razão das grandes disparidades financeiras, técnicas e de gestão que acometem a federação, sem mencionar o fato da Constituição não estimular a cooperação (SOUZA, 2005).

Assim como preconiza a Constituição no art. 198, inciso I, a lei 8.080/1990, via de regra, não traz uma exclusividade de atuação ou jurisdição para

\footnotetext{
${ }^{7}$ Art. 196. A saúde é direito de todos e dever do Estado, garantido mediante políticas sociais e econômicas que visem à redução do risco de doença e de outros agravos e ao acesso universal e igualitário às ações e serviços para sua promoção, proteção e recuperação.
} 
alguma esfera de governo na área da saúde. A União coordena, normatiza e determina padrões nacionais nas ações de governo. Os Estados atuam no acompanhamento, avaliação e controle das redes regionalizadas do SUS e prestam apoio técnico e financeiro, além de atuação complementar em coordenar e normatizar. Aos Municípios, por sua vez, cabem as funções de "planejar, organizar, controlar e avaliar as ações e os serviços de saúde e gerir e executar os serviços públicos de saúde", conforme o artigo 18, inciso I, da Lei 8080/90 (MACHADO, PALOTTI, 2015).

$\mathrm{Na}$ federação brasileira, os governos locais são fortemente dependentes das transferências de recursos federais e das regulamentações do Ministério da Saúde, uma vez que é da União a função de financiar a formular a política de saúde. Para a coordenação entre as unidades federadas o Poder Executivo federal se vale principalmente de portarias, deixando ao Congresso Nacional um papel secundário no que refere às políticas de saúde. $\mathrm{O}$ conteúdo destas portarias, na grande parte das situações, trata-se de condicionantes impostas a estados e munícipios para a transferência de recursos, notadamente, a adesão aos objetivos das políticas federais de saúde (ARRETCHE, 2004).

Foi por esta razão que no decorrer dos anos 1990 os Municípios e Estado aderiram em massa ao SUS, sendo que em maio de 2002, 5.537 dos 5.560 municípios, à época, tenham assumido a gestão integral ou parcial da saúde. Um exemplo é que em 1985, os municípios eram responsáveis por 9,3\% dos gastos em saúde, já em 1996, quase 10 anos após a promulgação da Constituição de 1988, o patamar atingia $28 \%$ (MEDICI, 2002, APUD ARRETCHE, 2004)

Há, no entanto, um contraponto. Nas políticas de saúde, estados e municípios participam e são representados por meio de conselhos, constituindo-se num espaço de negociação que impede que o Ministério da Saúde imponha regras de operação do SUS sem a consideração das ponderações locais (ARRETCHE, 2004). O que se denota, porém, é que o esquema para operação do SUS é bastante complexo em decorrência das regras que buscam coordenar as ações das três esferas federadas, sem mencionar a dependência financeira de Estados e Municípios em relação a União. Tal complexidade dificulta a efetivação das políticas públicas e do direito à saúde, o que acarreta uma significativa intervenção do Poder Judiciário para dirimir os conflitos.

Seja como for, apesar da complexidade, a Constituição de 88 tem como característica a universalidade de certos serviços sociais, notadamente, a saúde pública, cujo acesso não é mais restrito aos trabalhadores formais. Os princípios diretivos são a descentralização e a participação dos usuários. São vários os programas federais que a exigem a constituição de conselhos comunitários para o repasse de recursos. Assim, a participação é a regra (SOUZA, 2005).

\section{FORMAÇÃO DOS CONSELHOS MUNICIPAIS DE SAÚDE E PARTICIPAÇÃO POPULAR}

Especificadamente, no que tange aos conselhos de saúde, a participação da comunidade é um princípio das ações e serviços públicos e privados de saúde, de acordo com o artigo $7^{\circ}$, inciso VIII, da lei 8.080/1990, que regulamenta o artigo 198 da Constituição e o Sistema Único de Saúde (SUS). Já a lei 8.142/1990, em seu artigo $1^{\circ}, \S 2^{\circ}$, traz as atribuições e composição dos referidos conselhos, nos seguintes termos:

$\S 2^{\circ}$ O Conselho de Saúde, em caráter permanente e deliberativo, órgão colegiado composto por representantes do governo, prestadores de serviço, profissionais de saúde e usuários, atua na formulação de estratégias e no controle da execução da política de saúde na instância correspondente, inclusive nos aspectos econômicos e financeiros, cujas decisões serão homologadas pelo chefe do poder legalmente constituído em cada esfera do governo.

Percebe-se que a previsão legal impõe que o conselho seja formado por ampla representação, que inclui governo, prestadores de serviço de saúde, trabalhadores e usuários. Como já destacado anteriormente, a disseminação dos conselhos de saúde estaduais e municipais ocorreu, dentre outros motivos, em razão de que o repasse de recursos financeiros a estas unidades políticas restou condicionado a sua implementação por força do artigo $4^{\circ}$, inciso II, da lei 8.142/1990, o qual também determinou que a sua composição deve ser paritária, conforme previsto no decreto 99.438 de 7 de agosto de 1990. Referido decreto, porém, restou revogado pelo Decreto 5.839/2006. 
O Decreto 5.839/2006, em seu artigo $3^{08}$, traz a composição do Conselho Nacional de Saúde, no qual metade deve ser de representantes de entidades e dos movimentos sociais de usuários do SUS e a outra metade de representantes de entidades de profissionais de saúde, do governo e de prestadores de serviços de saúde. Ainda, o $\S 1^{\circ}$ do referido artigo, incisos I e II determina que a composição do grupo do artigo $3^{\circ}$, inciso II, seja dividido, $25 \%$ de representantes de entidades profissionais de saúde, incluída a comunidade científica e $25 \%$ por representantes do governo federal, CONASS, CONASEMS e prestadores de serviços e entidades empresariais da área da saúde.

Evidentemente, o Decreto 5.839/2006 versa sobre a composição do Conselho Nacional de Saúde, de forma que, a formação dos conselhos estaduais e municipais, devem adotar, por simetria, composição igual, paritária, tendo como modelo o conselho nacional, instituindo estes órgãos por leis próprias. É sempre oportuno lembrar que a organização política da saúde é tripartite e descentralizada, em três níveis de governo (federal, estadual e municipal) e, ainda, devem atender ao princípio da participação comunitária, que tem a função de controle social, corolário da democracia (LOBATO, 2009).

O exercício do controle social, por meio da participação direta nos conselhos, ganha ainda mais relevo na esfera municipal, uma vez que, grande parte do serviço de atenção básica ocorre pela gestão do município. Celia Lessa Kerstenetzky (2012, p. 261), citando E. Ostrom, afirma o seguinte:

Uma condição de efetividade das políticas sociais é a participação dos "beneficiários", seja no processo decisório e de monitoramento e controle da política, seja no consumo direto dos serviços de modo a transformá-lo em realizações efetivas ou "coproduzi-los".

A participação, no entanto, presume ação, atividade e efetiva interferência na gestão nas políticas públicas de saúde. Somente com a oportunidade de

\footnotetext{
${ }^{8}$ Art. $3^{\circ} \mathrm{O}$ CNS é composto por quarenta e oito membros titulares, sendo: I - cinqüenta por cento de representantes de entidades e dos movimentos sociais de usuários do SUS; e

II - cinqüenta por cento de representantes de entidades de profissionais de saúde, incluída a comunidade científica da área de saúde, de representantes do governo, de entidades de prestadores de serviços de saúde, do Conselho Nacional de Secretários de Saúde - CONASS, do Conselho Nacional de Secretários Municipais de Saúde - CONASEMS e de entidades empresariais com atividade na área de saúde.
}

participar diretamente nos processos decisórios é que o sujeito pode ter o real controle de sua vida e do desenvolvimento do ambiente em que vive. Participando o homem se educa como cidadão público e o seu exercício de voto para eleição de representantes passa a ter maior qualidade, com melhor capacidade de avaliar o cenário político. (PATEMAN, 1992, p. 145-146).

A questão que se coloca é o próprio exercício da democracia e da cidadania, sobre a efetividade da participação popular nos conselhos municipais de saúde, com enfoque nos usuários do serviço.

Robert A. Dahl (2008, p. 23-24), afirma que a democracia ideal precisa ter as seguintes características:

a. Participação efetiva, ou seja, a adoção de determinada política deve preceder que todos os membros de determinada associação tenham iguais oportunidades de dizer a sua opinião sobre como deveria ser tal política;

b. Igualdade na votação, compreendida como a oportunidade igual e efetiva de que todos possam votar nas tomadas de decisões finais e que todos os votos sejam contados por igual;

c. Aquisição de conhecimento da causa - todos devem ter iguais oportunidades de buscarem conhecimento e aprenderem sobre as alternativas políticas relevantes e suas consequências, dentro de um tempo razoável;

d. Controle da pauta - os membros de dada associação devem ter o poder de determinar e eleger os assuntos que serão pautados para discussão e aprovação ou não;

e. Inclusão - todos os cidadãos podem participar e serem dotados de todas as características anteriores e;

f. Direitos Fundamentais, no caso; que todas estas características já descritas sejam processos políticos previstos e protegidos como direitos fundamentais.

Já demonstrado anteriormente, a legislação brasileira garante formalmente, no âmbito de um conselho municipal de saúde, o direito de participação efetiva, a igualdade de votação, a possibilidade de todos participarem e pode-se afirmar que todas estas características encontram guarida constitucional, como decorrência dos direitos fundamentais. No entanto, o conhecimento da causa, sobre o quê de fato se está participando, a capacidade de compreender e contribuir para o que ali se está discutindo e a proposição de 
pautas factíveis, não podem ser garantidos pela mera previsão formal legal.

José Antonio Souto Paz (2010, p. 27) define o conteúdo da educação para a cidadania democrática como:

A educação para a cidadania democrática compreende a educação, formação, sensibilização, informação, práticas e atividades que têm como objetivo dotar os alunos de conhecimentos, habilidades e a compreensão e desenvolvimento de suas atitudes e comportamentos, dar-lhes a possibilidade de exercer e defender seus direitos democráticos e responsabilidades na sociedade, proporcionar-lhes a conhecer a diversidade de valores e desempenhar um papel ativo na vida democrática, com objetivo de promoção e proteção da democracia e do império da lei (TRADUÇÃO NOSSA). ${ }^{9}$

A educação do cidadão está diretamente conectada com a participação, pois a compreensão de si mesmo e da realidade que o cerca são condições para a sua atuação no espaço público. Somente o cidadão educado poderá se interessar pelos assuntos de sua comunidade e das demais comunidades conectadas a uma determinada demanda comum (GARCIA, 2009, p. 194). "A educação popular é um pressuposto fundante da cultura jurídica comunitária e participativa" (RIBAS, 2010, p. 96).

Destaque-se que participar efetivamente de uma comunidade implica numa concepção de responsabilidade e na compreensão das consequências do próprio comportamento e, numa concepção mais ampla, no cuidado com a coisa pública. Deve-se ter uma escola de pensamento, de participação ativa e de responsabilidade perante a comunidade, em que todos possam experimentar o real significado de cidadania, da dignidade da consciência de ser membro de uma sociedade (HELZEL, 2009, p. 118).

Numa sociedade que engaja seus membros na difícil, mas necessária tarefa de um cuidar do outro e de todos cuidarem da gestão dos assuntos comuns, observam-se padrões de prudência e justiça, que, no entanto, não exigem pessoas muito disciplinadas, mas

\footnotetext{
${ }^{9}$ La educación para la ciudadanía democrática comprende la educación, formación, sensibilización, información, prácticas y actividades que tienen como objetivo dotar a los alumnos de conocimientos, habilidades y la comprensión y el desarrollo de sus actitudes y comportamientos, darles la posibilidad de ejercer y defender sus derechos democráticos y responsabilidades en la sociedad, darles a conocer la diversidad de valores y de desempeñar un papel activo en la vida democrática, com miras a la promoción y protección de la democracia y el imperio de la ley.
}

apenas tenazes cidadãos responsáveis. Não se trata de sempre seguir regras, o desvio da regra é algo natural em uma comunidade. O que se precisa é que esta concepção de responsabilidade faça do cidadão uma base sob a qual se possa construir uma comunidade humana criativa e zelosa o bastante para o enfrentamento dos desafios atuais (BAUMAN, 2011, p. 386).

A educação para o exercício da cidadania é condição indispensável para a manutenção do sistema democrático, que precisa ser cultivado e protegido, pois do contrário, como já advertia Aristóteles, os sistemas políticos tendem a se degenerar e, em especial no caso da democracia, tendem a converter-se em demagogia (PAZ, 2010, p. 29). Por demagogia, pode-se aqui entender a participação em conselhos comunitários, como da saúde, em que vários sujeitos presentes meramente chancelam as decisões tomadas, sem refletir ou interferir no conteúdo daquilo que é refletido.

No entanto, no que corresponde ao exercício da cidadania e da prática democrática, a mera instrução geral do cidadão pode não ter os efeitos positivos que dela se esperaria. Sérgio Buarque de Holanda (2013, p. 165-166), escreveu a respeito:

É bem característico, para citar um exemplo, o que ocorre com a miragem da alfabetização do povo. Quanta inútil retórica se tem esperdiçado para provar que todos os nossos males ficariam resolvidos de um momento para o outro se estivessem amplamente difundidas as escolas primárias e o conhecimento do ABC. [...]. Cabe acrescentar que, mesmo independentemente desse ideal de cultura, a simples alfabetização em massa não constitui talvez um benefício sem-par. Desacompanhada de outros elementos fundamentais da educação, que a completem, é comparável, em certos casos, a uma arma de fogo posta nas mãos de um cego.

As previsões constitucionais, como no caso do Brasil, de que todos os indivíduos têm direito à educação, é entender que estes possuem o direito ao despertar das tradições e morais sociais, princípios fundadores de um Estado, que devem ser passados pela sociedade. Assim, por suposto, a educação apresenta-se com uma condição formadora do indivíduo necessária ao próprio desenvolvimento natural e não somente uma formação deste (PIAGET, 1973, p. 39).

É importante observar, todavia, que por mais instruído que seja o cidadão, a participação nos conselhos municipais de saúde implica em apreciar 
convênios, contratos, licitações, dentre inúmeros outros instrumentos dos quais seguem uma intrincada e numerosa legislação. Poucas pessoas possuem bom nível de conhecimento acerca destas temáticas.

Sobre esta questão, Niklas Luhmann (1985, p. 55) afirma que a complexidade atual do direito chegou a tal ponto que não é mais possível ao indivíduo conhecê-lo. Ainda, não bastasse o aumento da complexidade das relações sociais as quais o direito necessita regular, o próprio legislador amplia o desconhecimento do direito por meio da elaboração de leis cada vez mais obscuras e inacessíveis ao cidadão, tornando o direito opaco (CÁRCOVA, 2006, p. 43-45).

$\mathrm{O}$ direito e a lei que regulam a lógica da vida social, como uma espécie de guia para os cidadãos, de uma maneira paradoxal, não é conhecido, nem compreendido por estes (CÁRCOVA, 2006, p. 18). A existência de leis imprecisas, temporárias, meramente regulamentares, de prognóstico inseguro e o uso de conceitos jurídicos indeterminados pelo legislador vêm causando grande discussão sobre a indeterminação da legislação e do direito e é motivo de preocupação pela jurisprudência de muitos países (HABERMAS, 2003, p. 174).

O desconhecimento da lei e do direito, conveniente para poucos, obviamente tem efeitos muito mais dramáticos para as classes em situação de vulnerabilidade cultural e social (CÁRCOVA, 2006, p. 39). Se a pessoa ou o cidadão, membro de determinada ordem social, desconhece seus direitos, sobretudo os fundamentais, a própria Constituição do Estado do qual faz parte, sua participação na vontade e nos rumos da sociedade organizada por meio do Estado, bem como do direito, torna-se insustentável. Não é sem razão que as teorias contemporâneas sobre a democracia concluem que o que importa, na prática, é a participação da elite minoritária, e a não-participação do homem comum, apático, com pouco senso de eficácia política, pois sua falta de ação é vista como a principal salvaguarda contra a instabilidade (PATEMAN, 1992, p. 138-139).

O problema é que as sociedades democráticas atuais nada ou pouco fazem para instruir o cidadão a respeito do conteúdo da lei e do direito (CÁRCOVA, 2006, p. 39). Segue-se então uma crise de identidade dos nacionais que não sabem exatamente o conteúdo do significado de cidadão, sobretudo ante o fato de que "a nação não é apenas uma entidade política, mas algo que produz sentidos - um sistema de representação cultural”. As pessoas não são apenas cidadãos de uma nação, no sentido político-jurídico do termo, elas participam da concepção da nação tal como representada pela cultura nacional (HALL, 2011, p. 49).

Sobre a realidade brasileira, Paulo Freire (1996, p. 102) afirma que se faltaram condições no passado histórico-cultural, que tivessem dado, como a outros povos, uma constante de hábitos de solidariedade, tanto na política como socialmente, que fizeram dos brasileiros menos autênticos dentro de uma forma democrática de governo, é imperativo o aproveitando das atuais condições favoráveis à democratização, apelar para a educação, como ação social, por meio do qual se incorpore ao brasileiro estes hábitos.

Ainda, para além da educação e do conhecimento específico exigido para a apreciação de pautas nos conselhos municipais de saúde, observa-se, também, que nas democracias apenas uma minoria de pessoas de fato se propõe a dispor de seu tempo para atividades políticas, como participar de decisões do governo e da implementação de políticas públicas. O tempo é um recurso escasso e fixo, de forma que a participação direta, como nos conselhos, implica na perda de desenvolver outra atividade relevante para as pessoas. Isso implica que aqueles que têm mais tempo para tais atividades, têm maiores chances de influírem nas decisões políticas. Como a disposição de tempo não é igual entre todos, a depender também da classe social que possuem, tal assertiva significa uma desigualdade política entre os cidadãos com capacidade de influenciar as decisões. (DAHL, 2008, p. 68-69).

Pierre Bourdieu (2000, p. 10) também destaca tal situação:

A cultura dominante contribui para a integração real da classe dominante (assegurando uma comunicação imediata entre todos os seus membros e distinguindo-os das outras classes); para a integração fictícia da sociedade no seu conjunto, portanto, à desmobilização (falsa consciência) das classes dominadas; para a legitimação da ordem estabelecida por meio do estabelecimento das distinções (hierarquias) e para a legitimação dessas distinções.

Destarte, pode-se constatar que a participação com maior efetividade e qualidade num conselho municipal de saúde, como também nos demais conselhos comunitários, no exercício do controle social, depende de vários fatores, como nível de conhecimento geral, 
técnico, legal e específico da área da saúde, compreensão do real significado de cidadania, assim como, infelizmente, a classe social do indivíduo. O que se vê é que a lei formalmente determinou a participação, mas não há qualquer preocupação com a materialização desta participação, com a prévia capacitação dos cidadãos.

\section{ATUAÇÃO DO CONSELHO MUNICIPAL DE SAÚDE PALMAS-PR, DURANTE O} ANO DE 2017:

Para verificar se as observações dos teóricos já citados têm alguma consonância com a realidade, buscou-se analisar a atuação do conselho Municipal de Saúde de Palmas-PR. Com o objetivo de esclarecer como se deu a análise de atuação do conselho, optou-se pela divisão em quatro categorias: metodologia e coleta de dados; composição; reuniões e votações e frequência e participação efetiva.

\section{a) METODOLOGIA E COLETA DE DADOS:}

Para analisar como se deu a atuação do Conselho Municipal de Saúde e conferir sua pertinência em relação aos conceitos teóricos apresentados, optou-se pela análise de todas as atas de reuniões do conselho durante o ano de 2017. Este ano em particular foi escolhido por ser o mais recente e por um período completo, uma vez que a realização deste estudo foi concluída em meados de 2018.

A atas do conselho encontram-se arquivadas e impressas no escritório do órgão. Não há disponibilidade de acesso das atas pela internet, porém, em momento algum houve qualquer objeção pela secretaria do conselho e de sua presidência para que todas as atas fossem fotocopiadas, ressaltando-se que se tratavam de documentos públicos de livre acesso. Destaque-se que a numeração das atas não é exata, provavelmente por lapso da secretaria.

A coleta dos dados que embasam este artigo deu-se pela leitura minuciosa de todas as atas de reuniões e procurou-se ocultar nomes de conselheiros e a razão social ou denominação de empresas e entidades para preservação de suas imagens, na medida do possível.

Da mesma forma, o foco é em análises objetivas que tenham relação com o mecanismo de participação da democracia direta e da disposição ao exercício do controle social pelos cidadãos e não na apreciação da legalidade ou não daquilo que foi discutido, votado e aprovado.

\section{b) COMPOSIÇÃO:}

O Conselho Municipal de Palmas-PR, no ano de 2017, era composto por 40 conselheiros, sendo que 20 são titulares e 20 são suplentes, conforme consta em todas as atas de reunião do referido ano. Cada entidade representada possuía um titular e um suplente, dentre os conselheiros.

Consoante dispõe o Decreto 5.839/2006, em seu artigo $3^{\circ}$, incisos I e II e o $\S 1^{\circ}$ do mesmo artigo, incisos I e II, por simetria, o Conselho Municipal de Saúde de Palmas-PR deveria ser composto por $50 \%$ de representantes de entidades e dos movimentos sociais de usuários do SUS, $25 \%$ de representantes de entidades profissionais de saúde e a comunidade científica e $25 \%$ por representantes do governo, entidades de prestadores de serviços de saúde e entidades empresariais com atividade na área de saúde.

Ocorre que, analisando sua composição, percebe-se que o órgão não está constituído de acordo com os parâmetros do Decreto 5.839/2006, como se pode conferir na Tabela 1:

Tabela 1: Composição do Conselho Municipal de Saúde de Palmas-PR

\begin{tabular}{|c|c|c|}
\hline $\begin{array}{l}\text { Representantes } \\
\text { de entidades e dos } \\
\text { movimentos sociais de } \\
\text { usuários do SUS }\end{array}$ & $\begin{array}{l}\text { Representantes de } \\
\text { entidades profissionais } \\
\text { de saúde e a comunidade } \\
\text { científica }\end{array}$ & $\begin{array}{l}\text { Representantes do governo, } \\
\text { entidades de prestadores } \\
\text { de serviços de saúde e } \\
\text { entidades empresariais com } \\
\text { atividade na área de saúde }\end{array}$ \\
\hline Associação de Moradores & Auxiliares de Enfermagem & APAE \\
\hline Grupos da $3^{\text {a }}$ Idade & & Pastoral da Criança \\
\hline $\begin{array}{l}\text { Associação de } \\
\text { Quilombolas }\end{array}$ & Associação de Médicos & Asilo \\
\hline Sindicatos & Odontólogos & Escola Pública Municipal \\
\hline Igrejas Evangélicas & Assistentes Sociais & Hospital Privado \\
\hline Igreja Católica & \multirow{2}{*}{$\begin{array}{l}\text { Agentes Comunitários de } \\
\text { Saúde }\end{array}$} & Laboratórios e Farmacêuticos \\
\hline Observatório Social & & Departamento de Saúde \\
\hline \multicolumn{3}{|c|}{ Percentuais totais } \\
\hline $35 \%$ & $30 \%$ & $35 \%$ \\
\hline
\end{tabular}


Há ainda outra questão a ser considerada. Tomando o nome de cada conselheiro, por meio de pesquisas no Portal da Transparência da Câmara Municipal de Palmas ${ }^{10}$, que reúne informações de servidores do executivo e do legislativo do município, verificou-se que dos assistentes sociais, um é servidor público municipal e outro foi servidor. Auxiliares de enfermagem, enfermeiros, odontólogos e agentes comunitários de saúde, todos são servidores públicos municipais. A representante titular dos laboratórios e farmacêuticos também é servidora pública municipal.

Percebe-se, assim, que a possibilidade de influência do poder executivo municipal é imensa. É bem verdade que o servidor público municipal não necessariamente representará os interesses do governo, no entanto, tal fato poderia ser evitado por completo, elegendo-se conselheiros sem vínculo tão direto com o município.

Constata-se, também, que não se pode afirmar que a composição do conselho seja paritária, uma vez que, os representantes de entidades e movimentos sociais de usuários do SUS são apenas 35\% do total, quando deveriam ser 50\%. Perceba-se que APAE, Pastoral da Criança e Asilo, embora sejam instituições privadas de cunho filantrópico, todas prestam serviços na área de saúde, de forma que, não podem ser enquadradas na categoria de usuários, de acordo com a legislação.

Por fim, há evidente desequilíbrio na composição, pois os representantes de entidades profissionais de saúde somam $30 \%$ do total, quando deveriam ser $25 \%$. Da mesma forma, os representantes do governo, entidades de prestadores de serviços de saúde e entidades empresariais com atividade na área de saúde são $35 \%$ do total, quando também deveriam ser de $25 \%$.

Destarte, conclui-se que a composição do conselho não é exatamente paritária e não atende aos pressupostos legais exigidos e que, além disso, há excesso de influência do poder executivo municipal, uma vez que, 10 conselheiros são servidores públicos municipais.

\section{c) REUNIÕES E VOTAÇÕES:}

Durante o ano de 2017 foram realizadas 13 reuniões, sendo uma em cada mês, com exceção de junho,

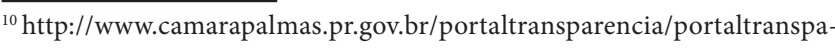
rencia.php
}

quando foram realizadas duas reuniões. Para cada um destes encontros foi lavrada uma ata a qual é assinada por todos os conselheiros e demais pessoas presentes. Somente os conselheiros votam.

Chama a atenção que, como visto antes, são 40 conselheiros que compõe o conselho, sendo 20 titulares e 20 suplentes. Ocorre que, nas reuniões em diversas vezes encontravam-se ambos, titular e suplente de dada entidade na reunião ou então nenhum dos dois, no entanto, no momento da votação, titular e suplente votaram, contabilizando-se, assim, dois votos. Com isso, resta evidente que as entidades com maiores frequências nas reuniões em que ambos os seus representantes compareçam, acabaram por exercer maior influência, ante a possibilidade de votação dobrada.

Outra constatação pertinente é que, embora tenham havidos alguns debates registrados nas atas, absolutamente tudo que foi tratado no ano de 2017, oficialmente, teve votação unânime, ou seja, sempre todos os conselheiros votaram no mesmo sentido, não importando quem representassem. Para deliberar sobre determinada questão, em nenhuma oportunidade foi registrada uma quantidade de votos contra e outra a favor, ou alguma abstenção, que indicasse uma divisão de opinião entre os conselheiros. A votação sempre foi unânime para aprovar ou não determinado ponto da pauta.

Embora a aprovação unânime sempre lance dúvidas sobre a confiabilidade do verdadeiro debate, não se pode, por si só, afirmar que houve algum tipo de manipulação ou encenação. A leitura completa do conteúdo das atas de reunião não parece indicar tal ardil, no entanto, há indício de inconsistência no caráter deliberativo do órgão, pois a deliberação sobre diversas questões ao longo de 2017, pressupõe a existência de, ao menos, alguma divergência de opinião entre os conselheiros. Ressalta-se que, a análise é pautada sobre o conteúdo registrado nas atas. É possível que tenham ocorrido divergências durante as reuniões, no entanto, se tal ocorreu, não foram registradas nos documentos.

\section{d) FREQUÊNCIA E PARTICIPAÇÃO EFETIVA:}

No que tange a frequência dos conselheiros, foram contabilizados os percentuais de frequência durante o ano de 2017, no qual ocorreram 13 reuniões. Para esse cálculo considerou-se como presente 
a entidade se o titular, o suplente, ou ambos estavam presentes.

O objetivo de se verificar a presença dos conselheiros deve-se ao fato de que a presença está diretamente ligada com os aspectos teóricos trazidos neste artigo, ou seja, se de fato está ocorrendo a mobilização do cidadão para reservar parte do seu tempo para as reuniões do Conselho Municipal de Saúde. A frequência é dos aspectos relacionados ao comprometimento e dedicação. A Tabela 2 mostra os percentuais de frequência de cada entidade e as médias de frequência de cada grupo do conselho, cuja composição deveria ser paritária, nos termos do Decreto 5.839/2006:

Tabela 2: Frequência dos Conselheiros em 2017

\begin{tabular}{|c|c|c|c|c|c|}
\hline $\begin{array}{l}\text { Representantes de entidades } \\
\text { e dos movimentos sociais de } \\
\text { usuários do SUS }\end{array}$ & $\%$ & $\begin{array}{l}\text { Representantes de entidades } \\
\text { profissionais de saúde e a } \\
\text { comunidade científica }\end{array}$ & $\%$ & $\begin{array}{l}\text { Representantes do governo, } \\
\text { entidades de prestadores de } \\
\text { serviços de saúde e entidades } \\
\text { empresariais com atividade } \\
\text { na área de saúde }\end{array}$ & $\%$ \\
\hline Associação de Moradores & 30,7 & Auxiliares de Enfermagem & 69,2 & APAE & 61,5 \\
\hline Grupos da $3^{\text {a }}$ Idade & 69,2 & Enfermeiros & 92,3 & Pastoral da Criança & 84,6 \\
\hline Associação de Quilombolas & 61,5 & Associação de Médicos & 61,5 & Asilo & 69,2 \\
\hline Sindicatos & 100 & Odontólogos & 100 & Escola Pública Municipal & 61,5 \\
\hline Igrejas Evangélicas & 100 & Assistentes Sociais & 61,5 & Hospital Privado & 84,6 \\
\hline Igreja Católica & 30,7 & \multirow{2}{*}{$\begin{array}{l}\text { Agentes Comunitários de } \\
\text { Saúde }\end{array}$} & \multirow{2}{*}{76,9} & Laboratórios e Farmacêuticos & 84,6 \\
\hline Observatório Social & 69,2 & & & Departamento de Saúde & 92,3 \\
\hline \multicolumn{6}{|c|}{ Frequência média por grupo de Conselheiros em 2017} \\
\hline $65,9 \%$ & & \multicolumn{2}{|l|}{$76,9 \%$} & $76,9 \%$ & \\
\hline
\end{tabular}

Como se pode verificar, o grupo de menor frequência (69,5\% de presenças) é justamente dos representantes de usuários do SUS, ao passo que, os demais grupos, tiveram frequência média igual de $76,9 \%$. Chama atenção também que os representantes da Associação de Moradores, suposto grupo que concentraria grande interesse no bom funcionamento do SUS, tenha obtido apenas $30,7 \%$ de frequência, ou seja, comparecimento em apenas 4 das 13 reuniões realizadas.

Dos percentuais médios de presença por grupos, novamente, fica evidente e reforçado o desequilíbrio e prejuízo na paritariedade do conselho, pois além da composição que beneficia, irregularmente como visto antes, representantes do governo, prestadores de serviço e profissionais de saúde, a frequência destes grupos é significativamente superior ao dos usuários do SUS. Sem frequência, não há participação e deliberação.

Observa-se também que a maior participação de entidades que detém maior poder político e econômico, notadamente, o departamento de saúde e os representantes do hospital privado, laboratórios e farmacêuticos, pode significar que o interesse dessas classes tem preponderado.

Importante, da mesma forma, é ressaltar que não se sabe a motivação das ausências dos conselheiros, pois tal expediente não foi registrado nas atas de reunião, não sendo possível auferir nesta análise as razões das faltas.

Em relação a efetiva participação dos conselheiros, quando presentes, também se constatou um significativo desequilíbrio de acordo com o conteúdo das atas. A pauta é sugerida pela presidência do conselho e é enviada com antecedência na convocação das reuniões, no entanto, não observou nenhuma sugestão de pauta por parte dos conselheiros, notadamente, dos representantes de usuários do SUS.

Sobre o grupo dos usuários do SUS, verifica-se que o representante das igrejas evangélicas, que ocupa a vice-presidência, foi bastante atuante durante o ano de 2017, fazendo constantes observações e questionamentos. Para além do vice-presidente, em uma única oportunidade, numa única reunião, um representante dos sindicatos pediu maiores esclarecimento sobre determinado contrato (Ata de 12 de setembro de 2017) e o representante do observatório social, também, numa única oportunidade, pediu a palavra para discorrer genericamente sobre a motivação dos servidores públicos na área da saúde no município (A ta de 14 de novembro de 2017). Com exceção destas intervenções, absolutamente, nenhum conselheiro representante do 
grupo de usuários do SUS fez qualquer intervenção, questionamento ou pediu a palavra durante todo o ano de 2017.

Esta falta de participação efetiva, de pedir a palavra, manifestar a opinião, debater e propor pautas ou discussões, inclusive, foi discutida em duas oportunidades, eu reuniões distintas. Em uma o vice-presidente instigou aos conselheiros para participarem mais e não saírem mudos e calados das reuniões (Ata de 12 de maio de 2017) e, em outra oportunidade, um representante dos laboratórios e farmacêuticos discorreu sobre a ideia de realizar um curso de capacitação para os conselheiros de saúde para que participassem mais e fossem mais ativos (Ata de 14 de novembro de 2017). Nenhuma providência, neste sentido, no ano de 2017, foi tomada.

Pode-se constatar assim que os próprios conselheiros, que foram mais atuantes, independente do grupo que representavam, possuíam e manifestaram preocupação com a participação inócua e sem atividade de grande parte dos demais membros. Logo, há evidente prejuízo em relação a efetividade da participação cidadã no conselho que, sendo órgão também fiscalizador, precisa, necessariamente, de engajamento e intervenção constante.

\section{CONSIDERAÇÕES FINAIS}

Da análise dos dados coletados pelas atas de reunião de 2017 do Conselho Municipal de Saúde de Palmas-PR, verifica-se que a participação no referido Conselho não atende os requisitos legais mínimos exigidos, tampouco pode ser qualificada como efetiva, que atenda ao conceito de cidadania, no sentido do exercício do controle social, de eficiente fiscalização e formulação de políticas públicas na área da saúde, como apontado por Lenaura de Vasconcelos Costa Lobato (2009).

A composição do conselho não é paritária, apenas 35\% dos conselheiros são representantes de entidades e movimentos sociais de usuário do SUS, quando este percentual deveria ser de $50 \%$, segundo o Decreto 5.839/2006. Não bastasse tal fato, restou evidente que durante todas as reuniões a participação desses conselheiros foi praticamente na condição de ouvintes, com pouquíssimas intervenções ou questionamentos. É também deste grupo, que contém os representantes da camada mais vulnerável e com menor influência política e econômica, a menor frequência nas reuniões. A aquisição de conhecimento da causa, um dos requisitos apontados por Robert A. Dahl (2008, p. 23-24) para a existência de uma democracia ideal, ao que parece, não se fez presente para grande parte dos conselheiros, notadamente daqueles que representam os usuários do SUS.

Discorreu-se ao longo do texto na importância da formação do cidadão, de uma educação com qualidade, para que se instale condições mínimas de participação popular com eficiência. O conteúdo das atas de reunião revelou, de fato, que muitos dos assuntos ali tratados são bastante técnicos e exigem conhecimento específico de diversas áreas do conhecimento, como administração pública, contabilidade, legislação e políticas públicas.

Assim, parece claro que uma política de formação para atuação neste e em outros conselhos é uma medida imperativa, que corrobora com o pensamento de Jose Antonio Souto Paz (2010, p. 29) de que a educação para o exercício da cidadania é condição para manutenção do sistema democrático. O mesmo autor, citando, Aristóteles, afirmou que, do contrário, corria-se o risco da democracia transformar-se em demagogia.

É bem verdade que análise apenas de atas de reunião não é capaz de fornecer elementos $100 \%$ seguros de como se deram os referidos encontros, se o que foi registrado corresponde ao ocorrido e debatido de fato, contudo, a assinatura dos conselheiros demonstra sua concordância com o registro. No caso em tela, vislumbra-se sim parcela de demagogia nas participações, no sentido de se realizar um ato apenas formalmente, ante a exigência legal, uma vez que, todos os temas debatidos, sem exceção, foram aprovados por unanimidade durante todo o ano de 2017.

Essa unanimidade também é forte indicativo de que há dirigismo na escolha das pautas, uma vez que, há evidente desequilíbrio na composição do conselho, com forte atuação do poder executivo municipal, tendo em vista que, grande parte dos conselheiros são servidores públicos municipais, muito embora estejam atuando como representantes de categorias profissionais ou de prestadores de serviço na área de saúde. A liberdade na formação de pautas e agendas também é um requisito para uma democracia ideal no pensamento de Robert A. Dahl (2008, p. 23-24). Tal fato não poderia ocorrer de forma alguma, uma vez que, o 
conselheiro precisa de isenção e ausência de pressão externa para exercício do controle social. Não se pode afirmar se de fato há alguma intervenção do governo municipal, no entanto, a mera possibilidade disso já inviabiliza a atuação dos conselheiros.

Deste modo, a fiscalização sobre a condução do governo na saúde ficou claramente prejudicada, lançando dúvida sobre a legitimidade de atuação do conselho. Não pode deixar de notar também um forte componente de classe, como aventado por Pierre Bourdieu (2010, p. 10), já que os representantes do governo e de entidades empresariais tiveram atividade muito mais contundente no conselho, assim como frequência. Percebe-se, pelo conteúdo das atas, um claro controle sobre quais são os assuntos pautados nas reuniões.

A prática do Conselho Municipal de Saúde de Palmas-PR demonstra que a mera previsão de instrumentos de democracia direta, que garantam a participação do cidadão com paridade política em conselhos, não confere garantia alguma de que o controle social será de fato exercido. Portanto, o pensamento de Paulo Freire (1996, p.102), antes destacado, continua a não ser observado nesta realidade municipal, pois não se pode afirmar que a ação social tenha se incorporado no cidadão como um hábito e que sem o apelo à educação, a democratização realmente pode ser convertida em mero processo demagógico.

\section{REFERÊNCIAS:}

ARRETCHE, Marta. Federalismo e Políticas Sociais no Brasil: problemas de coordenação e autonomia. São Paulo em Perspectiva. São Paulo, v. 18, n. 2, p. 17-26, junho de 2004. Disponível em:

http://www.scielo.br/scielo.php?script=sci arttext\&pid $=$ S0102-88392004000200003\&lng $=$ en \&nrm $=\overline{\mathrm{i}}$ so . Acesso em 05 de junho de 2018.

BAUMAN, Zygmunt. Vida em fragmentos: sobre a ética pós-moderna. Tradução de Alexandre Werneck. Rio de Janeiro: Zahar, 2011.

BOURDIEU, Pierre. O Poder Simbólico. Tradução de Fernando Tomaz. $3^{\mathrm{a}}$ ed. Rio de Janeiro: Bertrand Brasil, 2000 .

BRASIL. Constituição da República Federativa do Brasil. Diário Oficial da República Federativa do Brasil. Brasília, 05 de outubro de 1988 .
BRASIL. Lei 8.080 de 19 de setembro de 1990. Diário Oficial da União. Brasília, 20 de setembro de 1990.

BRASIL. Lei 8.142 de 28 de dezembro de 1990. Diário Oficial da União. Brasília, 31 de dezembro de 1990.

BRASIL. Decreto no 5.839 de 11 de julho de 2006. Diário Oficial da União. Brasília, 12 de julho de 2006.

CÁRCOVA, Carlos María. La Opacidad del Derecho. $2^{\mathrm{a}}$ ed. Madrid: Trotta, 2006.

DAHL, Robert A. La Igualdad Política. Tradução de Liliana Andrade Llanas. Buenos Aires: Fondo de Cultura Económica, 2008.

FREIRE, Paulo. Educação como Prática da Liberdade. $22^{\mathrm{a}}$ ed. Rio de Janeiro: Paz e Terra, 1996.

GARCIA, Marcos Leite. Direitos Fundamentais e Transnacionalidade: um estudo preliminar. In CRUZ, Paulo Márcio, STELZER, Joana. (org.) Direito e Transnacionalidade. Curitiba: Juruá, 2009.

HABERMAS, Jürgen. Direito e Democracia entre a Facticidade e validade II. Tradução de Flávio Beno Siebeneichler. $2^{\text {a }}$ ed. Rio de Janeiro:Tempo Brasileiro, 2003.

HALL, Stuart. A Identidade Cultural na Pós-Modernidade. Tradução de Tomaz Tadeu da Silva e Guacira Lopes Louro. $11^{\mathrm{a}}$ ed. Rio de Janeiro: DP\&A, 2011.

HELZEL, Paola B. Educare alla cittadinanza nelle società multietniche. In PAZ, José Antonio Souto (dir.), GALVÁN, Esther Souto (coord.). Educación, Democracia y Ciudadanía. Madrid: Dykinson S. L, 2010.

HOLANDA, Sérgio Buarque de. Raízes do Brasil. $26^{\mathrm{a}}$ ed. São Paulo: Companhia das Letras, 2013.

IBGE. Instituto Brasileiro de Geografia e Estatística. O Brasil em Síntese. Panorama do município de Palmas, Estado do Paraná. Disponível em https://cidades.ibge.gov.br/brasil/ pr/palmas/panorama Acesso em 28 de abril de 2018.

IPARDES. Caderno Estatístico: Município de Palmas. Curitiba: Instituto Paranaense de Desenvolvimento Econômico e Social, julho de 2018. Disponível em http://www.ipardes.gov.br/cadernos/MontaCadPdf1. php? Municipio $=84670$.

Acesso em 01 de julho de 2018;

KERSTENETZKI, Celia Lessa. O Estado de Bem-Estar Social na Idade da Razão: a reinvenção do estado social no mundo contemporâneo. Rio de Janeiro: Elsevier, 2012;

LOBATO, Lenaura de Vasconcelos Costa. Dilemas da Institucionalização de Políticas Sociais em Vinte Anos da Constituição de 1988. Ciência \& Saúde Coletiva. Rio de Janeiro, v. 14, n. 3, p. 721-730, 2009. Disponível em: http:// www.scielo.br/pdf/csc/v14n3/en_08.pdf Acesso em 30 de maio de 2018; 
LUHMANN, Niklas. Sociologia do Direito II. Tradução de Gustavo Bayer. Rio de Janeiro: Tempo Brasileiro, 1985;

MACHADO, José Angelo, PALOTTI, Pedro Lucas de Moura. Entre cooperação e centralização: Federalismo e políticas sociais no Brasil Pós-1988. Revista Brasileira de Ciências Sociais. São Paulo, v. 30, n. 88, p. 61-82, junho de 2015. Disponível em http://www.scielo.br/pdf/rbcsoc/ v30n88/0102-6909-rbcsoc-30-88-0061.pdf Acesso em 29 de maio de 2018.

MARTín, Carlos de Cabo. Teoría Constitucional de La Solidaridad. Madrid: Marcial Pons, 2006;

PALMAS. Ata de Reunião no 01 de 30 de janeiro de 2017. Conselho Municipal de Saúde. Palmas, 2017;

PALMAS. Ata de Reunião no 02 de 14 de fevereiro de 2017. Conselho Municipal de Saúde. Palmas, 2017;

PALMAS. Ata de Reunião no 02 de 28 de março de 2017. Conselho Municipal de Saúde. Palmas, 2017;

PALMAS. Ata de Reunião no 03 de 20 de abril de 2017. Conselho Municipal de Saúde. Palmas, 2017;

PALMAS. Ata de Reunião no 04 de 12 de maio de 2017. Conselho Municipal de Saúde. Palmas, 2017;

PALMAS. Ata de Reunião no 05 de 13 de junho de 2017. Conselho Municipal de Saúde. Palmas, 2017;

PALMAS. Ata de Reunião no 06 de 27 de junho de 2017. Conselho Municipal de Saúde. Palmas, 2017;

PALMAS. Ata de Reunião no 06 de 18 de julho de 2017. Conselho Municipal de Saúde. Palmas, 2017;

PALMAS. Ata de Reunião no 07 de 11 de agosto de 2017. Conselho Municipal de Saúde. Palmas, 2017;

PALMAS. Ata de Reunião no 08 de 12 de setembro de 2017. Conselho Municipal de Saúde. Palmas, 2017;

PALMAS. Ata de Reunião no 09 de 10 de outubro de 2017. Conselho Municipal de Saúde. Palmas, 2017;

PALMAS. Ata de Reunião no 10 de 14 de novembro de 2017. Conselho Municipal de Saúde. Palmas, 2017;

PALMAS. Ata de Reunião no 11 de 12 de dezembro de 2017. Conselho Municipal de Saúde. Palmas, 2017;

PALMAS. Portal da Transparência. Câmara Municipal de Palmas. Disponível em http://www.camarapalmas.pr.gov.br/ portaltransparencia/portaltransparencia.php Acesso em 26 de abril de 2018;

PATEMAN, Carole. Participação e Teoria Democrática. Tradução de Luiz Paulo Rouanet. São Paulo: Paz e Terra, 1992;

PAZ, José Antonio Souto. Educación y ciudadanía. Contexto histórico y cuestiones actuales. In PAZ, José Antonio
Souto (dir.), GALVÁN, Esther Souto (coord.). Educación, Democracia y Ciudadanía. Madrid: Dykinson S. L, 2010;

PÉREZ LUÑO, Antonio E. Los Derechos Fundamentales: Temas Clave de La Constitución Española. 11 ${ }^{\mathrm{a}}$ ed. Madrid: Tecnos, 2013;

PIAGET, Jean. Para onde vai a Educação? Tradução de Ivette Braga. Rio de Janeiro: UNESCO, 1973;

RIBAS, Luiz Otávio. Pluralismo Jurídico, Direitos Humanos e Educação Popular. In WOLKMER,Antonio Carlos, VERAS NETO, Francisco Q. LIXA, Ivone M. (org). Pluralismo Jurídico: os novos caminhos da contemporaneidade. São Paulo: Saraiva, 2010;

SARLET, Ingo Wolfgang. A Eficácia dos Direitos Fundamentais: uma teoria geral dos direitos fundamentais na perspectiva constitucional. $10^{\mathrm{a}} \mathrm{ed}$. Porto Alegre: Livraria do Advogado Editora, 2011;

SOUZA, Celina. Federalismo, desenho constitucional e instituições federativas no Brasil pós-1988. Revista de SociologiaePolitica.Curitiba,n.24,p. 105-121,Junhode2005. Disponível em: http://www.scielo.br/scielo.php?script=sci arttext\&pid=S0104-44782005000100008\&lng=en\&nrm $=\mathrm{i}$ so . Acesso em 04 de junho de 2018. 